\title{
A Global Perspective on Safe Nanotechnology
}

XVIII World Congress on Safety and Health at Work June 30, 2008 16:00-18:30

COEX Convention and Exhibition Center

Seoul, Korea

100

든므

\section{4 룽이}

\section{oomm} AL르명

S I DENALI 


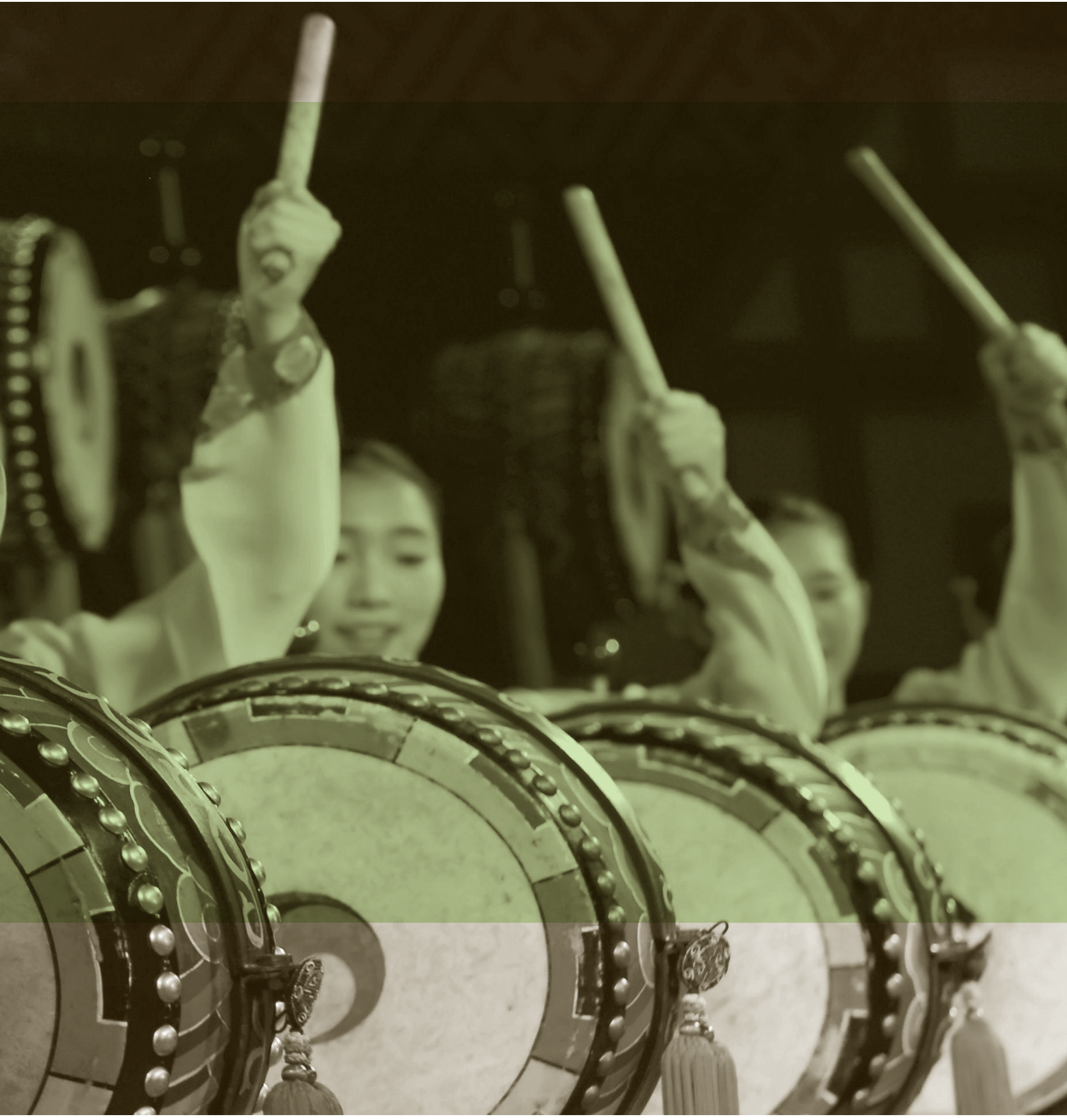




\section{A Global Perspective on Safe Nanotechnology}

XVIII World Congress on Safety and Health at Work June 30, 2008 16:00-18:30

COEX Convention and Exhibition Center, Seoul, Korea

\section{Co-Chairpersons:}

Max R. Lum

National Institute for Occupational Safety and Health (NIOSH)

United States of America

Markus Berges

German Social Accident Insurance (DGUV)

Federal Republic of Germany 


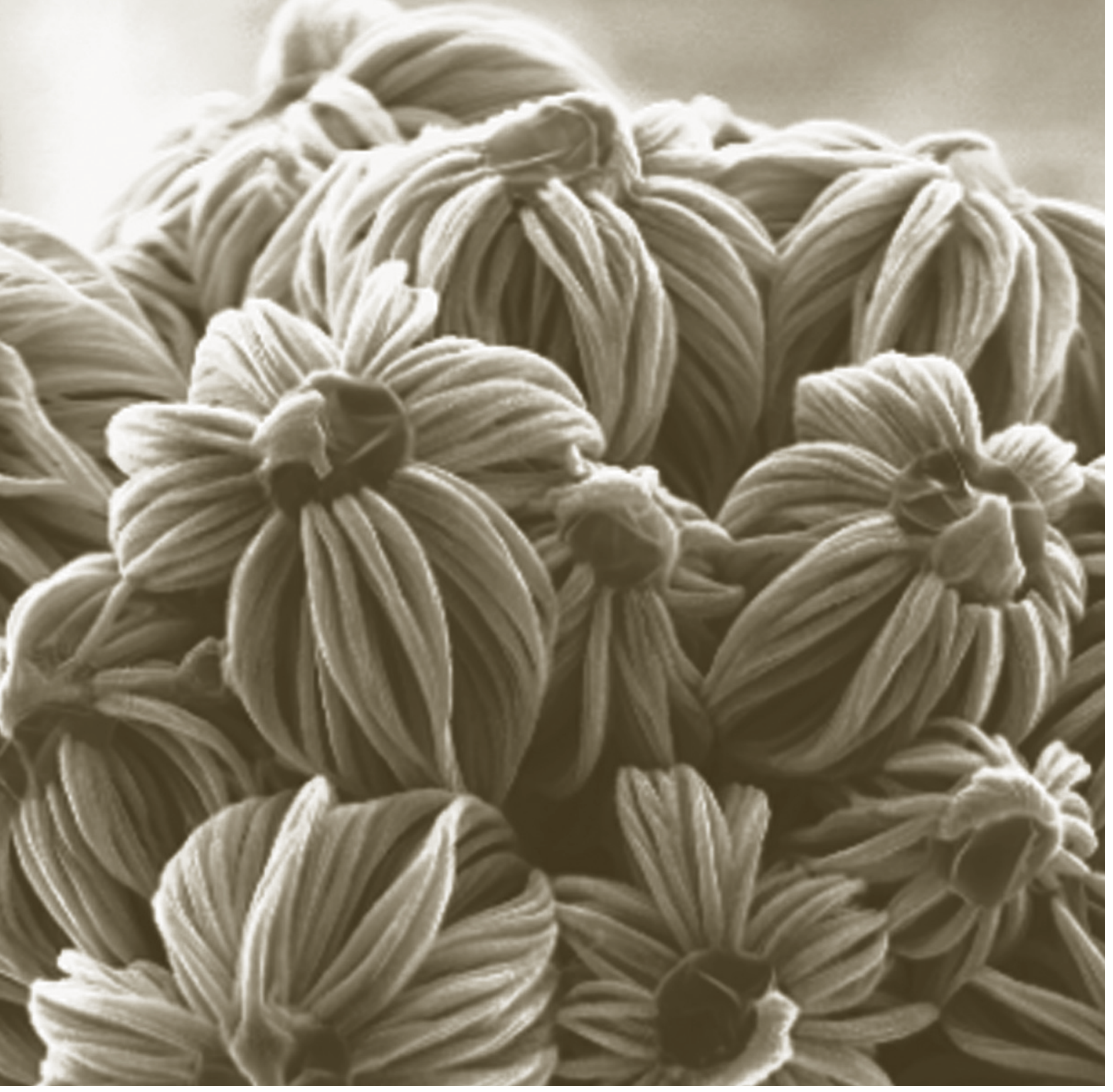

Flower Bouquet, a 3-D nanostructure grown by controlled nucleation of silicon carbide nanowires on Gallium catalyst particles. As the growth proceeds, individual nanowires 'knit' together to form 3-D structures. Credit: Ghim Wei Ho and Professor Mark Welland, Nanostructure Center, University of Cambridge. Courtesy: National Science Foundation 


\section{Forward}

The past decade has seen intense interest in developing technologies based on the unique behavior of nanometer-scale (nanoscale) structures, devices, and systems which has lead to the rapidly expanding and highly diverse field of nanotechnology.

Nanotechnology is somewhat loosely defined, although in general terms it covers engineered structures, devices, and systems that have a length scale between I and $\mathrm{o}$ oo nanometers. At these length scales, materials begin to exhibit unique properties that affect physical, chemical, and biological behavior. Researching, developing, and utilizing these properties is at the heart of new technology.

One of the best channels to achieve the goal of keeping workers safe from potential harm of this new technology is by collaborating on research in the field of nanotechnology. A recent symposium held at the XVIII World Congress on Safety and Health at Work, "Approaches to Safe Nanotechnology: A Global Perspective", brought seven international scientists together to discuss the topic. The lessons learned and the importance of global collaboration on nanotechnology safety and health research were discussed.

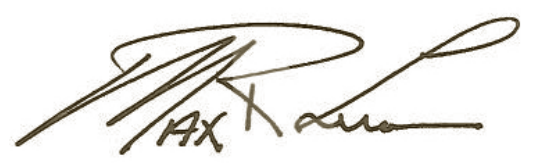

Max Lum, EdD MPA

Associate Director, Office of Health Communication and Global Collaborations $\mathrm{NIOSH}$ - CDC 


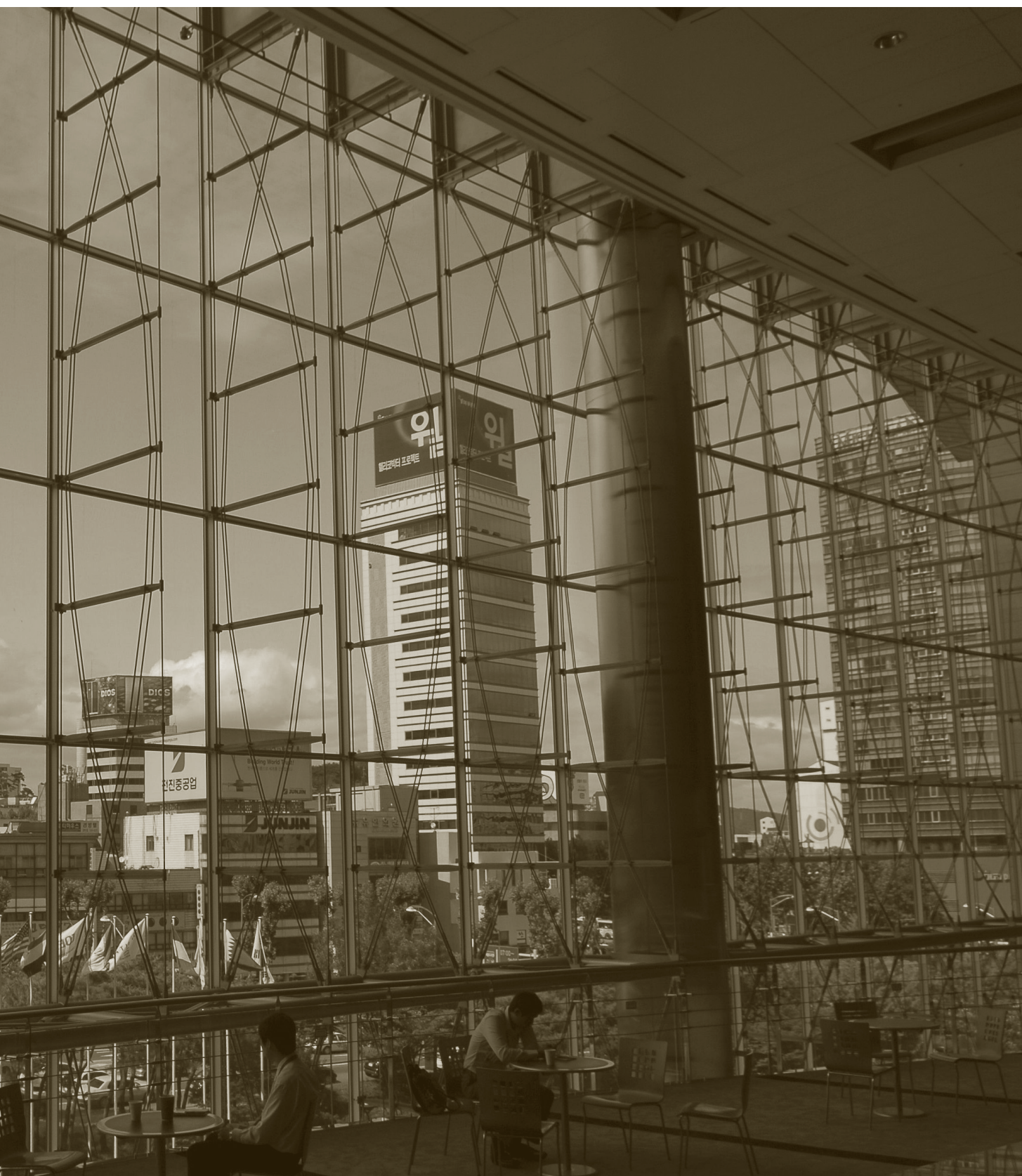




\section{Table of Contents}

Guidelines for Safe Nanotechnology

Presenter: Max Lum ............................

Korean Actions for Safety Nanotechnology

Presenter: Jeong Sun Yang $\ldots \ldots \ldots \ldots \ldots \ldots \ldots \ldots \ldots \ldots \ldots \ldots$

Actions for Safe Nanotechnology in Japan

Presenter: Ogawa Yasutaka ........................... 4

Promoting Safe Use of Nanotechnologies in Australian Workplaces:

The Nanotechnology OHS Research and Development Program

Presenter: Tom Fisher .......................... 5

Measuring Inhalation Exposure to Nanoparticles;

Current Methods and Requirements

Presenter: Olivier Witschger . . . . . . . . . . . . . . . . . . .6

Measuring Exposure to Ultrafine and Nanoparticles at Workplaces

Presenter: Markus Berges......................... 9

A Global Review of Safe Nanotechnology Initiatives: Research Gaps and Future Issues

Presenter: Sergio Iavicoli ............................ 10

Resources (organized by the presenter) $\ldots \ldots \ldots \ldots \ldots \ldots \ldots 11$ 


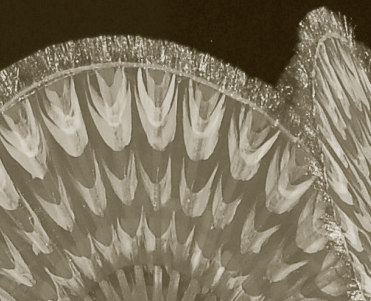

- Jimmiry a

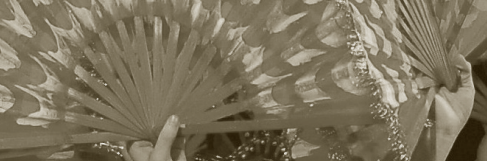

2t.

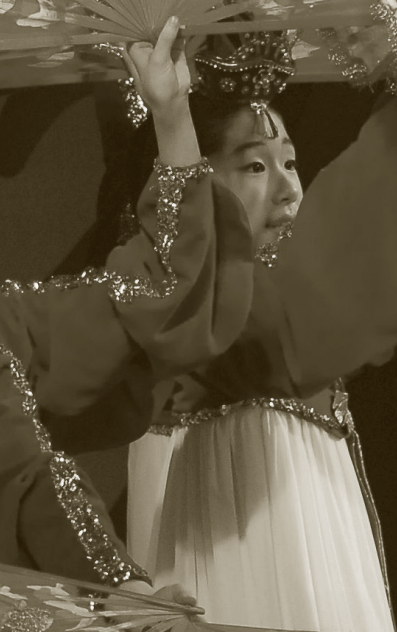

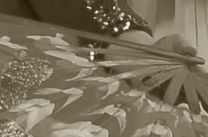

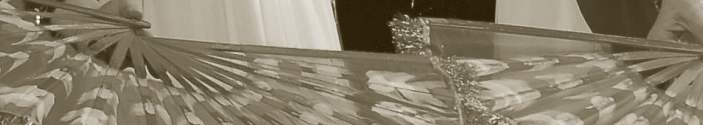
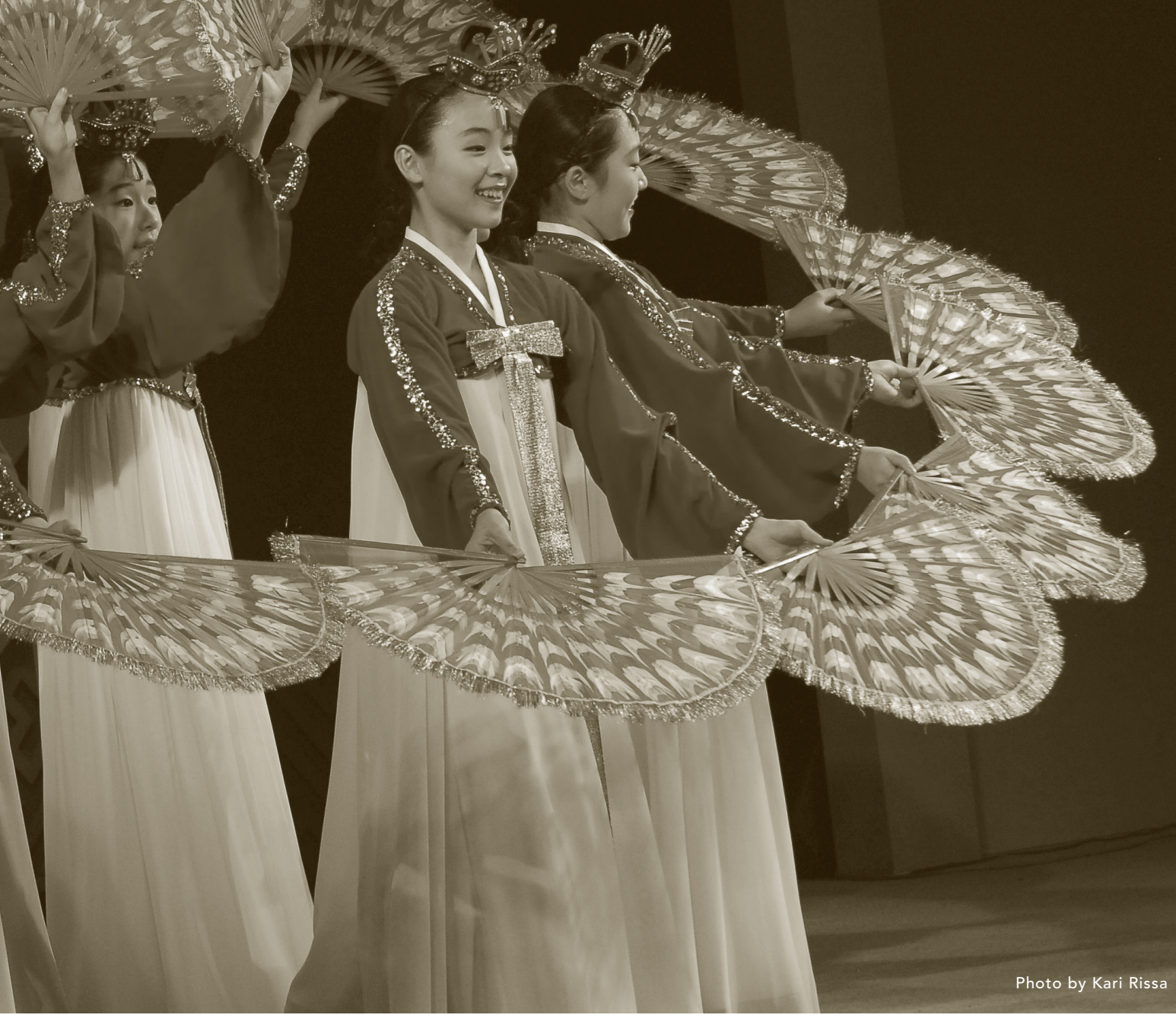


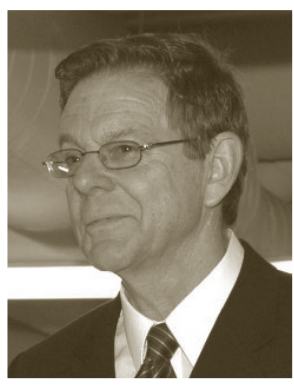

\section{Guidelines for Safe Nanotechnology}

Max R. Lum

National Institute for Occupational Safety and Health (NIOSH), United States

Director, Office of Health Communication and Global Collaboration

395 E St. SW, Suite 9200

Washington, DC 20201 USA

Tel: + 202-245-0644 Fax: + 202-245-0648

Email: mrl1@cdc.gov

Website: www.cdc.gov/niosh

Nanotechnology is revolutionizing the development of new materials with unprecedented functional properties. The field of nanotechnology will likely transform a broad range of consumer, medical, and industrial sectors. As with any new technology, we are faced with many unknowns; all of which raise questions concerning occupational safety and health. In the United States, the National Institute for Occupational Safety and Health (NIOSH) is committed to ensuring high-quality research for worker protection as nanotechnology develops.

It is imperative that the scientific community come together to advance our understanding of nanotechnology and its implications in the workplace. It is paramount for nations to share any relevant information or experience pertaining to the field of nanotechnology based on a broad and strong foundation of basic research. Through continued coordination with other governments, industry, and other stakeholders, the occupational safety and health community can remain a leader in the responsible development of nanotechnology.

As our knowledge grows, NIOsH plans to provide valuable guidance for the safe handling of nanoparticles and other safe approaches to nanotechnology. This effort will evolve as the technology advances, and our knowledge and experience grow.

NIOsH developed the first version of Approaches to Safe Nanotechnology in October 2005. A revised version with updates from NIOsH research results was released in March 2009 as NIOSH Publication No. 2009-I 25. The document describes the NIOsH strategy for addressing priority research on the occupational safety and health aspects of nanomaterials to understand the potential risks that nanotechnology may have to workers. The approach is driven by the breath of issues; from exposure, to managing risks, and the overarching need to measure and characterize nanomaterials in various work environments. Our research approach and framework continue to emphasize understanding and prioritizing potential risks as well as the mechanisms and strategies to manage such risks. 


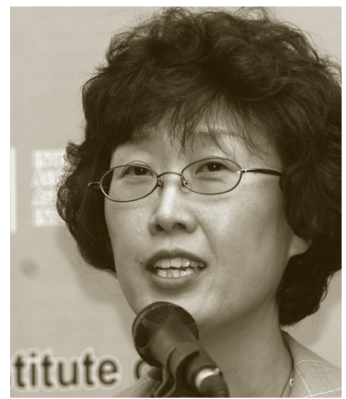

Korea is one of the major developers of nanotechnology. According to the 2nd comprehensive plan for the development of nanotechnology (2005), the estimate gross investment for developing nanotechnology is expected to be 4,855 million USD from 2006-2015. Due to rising interest on social impacts of nanotechnology, the issue of safe nanotechnology was adopted as one of four main goals in the 2nd comprehensive plan.

The Korean government is well aware of nano safety and conducts many activities related with these concerns. KоsнA held the international symposium on nano safety titled "The Health Risks Associated with Nanotechnology" in 2005. It triggered concerns about safe nanotechnology especially with the protection of workers from exposure to the unknown hazards of nanoparticles. It was suggested that a multidisciplinary team approach is needed for research on nano safety. The main approach for nano safety in our occupational safety and health issues are categorized by three major fields: 1) toxicity and risk assessment, 2) analytical method and exposure monitoring, and 3) exposure mitigation and hazard communication information contained in Material Safety and Data Sheets.

коSHA has performed hazard assessments via inhalation and skin absorption for non-purposely induced ultra fine particles \& aerosols in the workplace, such as Red 195 dye, $\mathrm{CrO}_{3}$ mist (MPS: 1.0 um, 2001), metal working fluid aerosol (MPS: 1.56 um, 2004), $\mathrm{SiO}_{2}$ in ultra fine particles (2005), and welding fume in cynomolgus monkeys (MPS: 0.579 um, 2006).

Several studies on cytotoxicity in vitro with commercial nanoparticles such as $\mathrm{Ag}, \mathrm{Cu}, \mathrm{Fe}$, $\mathrm{Ni}$, Magnetic nanoparticles, single-walled carbon nanotubes, multi-walled carbon nanotubes, and spiral and straight carbon nano fibers were performed by козна (2005). In vitro mammalian chromosomal aberration test for Fullerene followed (2007). Monitoring multiwalled carbon nanotube exposure in a carbon nanotube research facility was performed using a multidisciplinary team approach (2008). KOsHA participates in the Organisation for Economic Co-operation and Development (OECD) testing program for I 4 manufactured nanomaterials. 
There is a great deal of research under way. Until more information on toxicity of nanomaterials is collected, we still need safe guidelines for the workers who work with nanomaterials and researchers in nano facilities. A draft of guidelines for safe treatment of nanomaterials in the workplace was submitted to the Korean Occupational Safety and Health Agency in 2008. The Ministry of Labor is aware of the affairs of legislation such as new chemical notification, Threshold Limit Value (TLV), and MSDs for nanomaterials in the Occupational Safety and Health Act.

The Ministry of Environment (MOE) implemented the nano safety project, Ecotechnomia21, to support the establishment of an infrastructure necessary to minimize potential risks derived from the manufacture, distribution, and disposal of nanomaterials and nanomaterialcontaining products (until 20I0, 0.5 million USD per year, in total 3 million USD). The project is designed to be used for the supportive data to international cooperation activities of the Working Party on Manufactured Nanomaterials (WPMN) under the OECD.

The Korean Food and Drug Administration's support for a research project on the toxicity of nanomaterials for food, drug, and cosmetics was I.2 I million USD in 2007. The Korea Agency for Technology and Standards (KATs) under the Ministry of Knowledge and Economics (MKE) participates in ISO/TC 229 for international standardization on definitions, characterization, and evaluation.

Titanium dioxide microsphere 1-50 microns in diameter with (approximately) closed-packed spherical inclusions. These can be thought of as small "photonic crystallites," which are expected to scatter light very efficiently. Credit: Sascha Klein, Fred Lange and David Pine, University of California, Santa Barbara. Courtesy: National Science Foundation

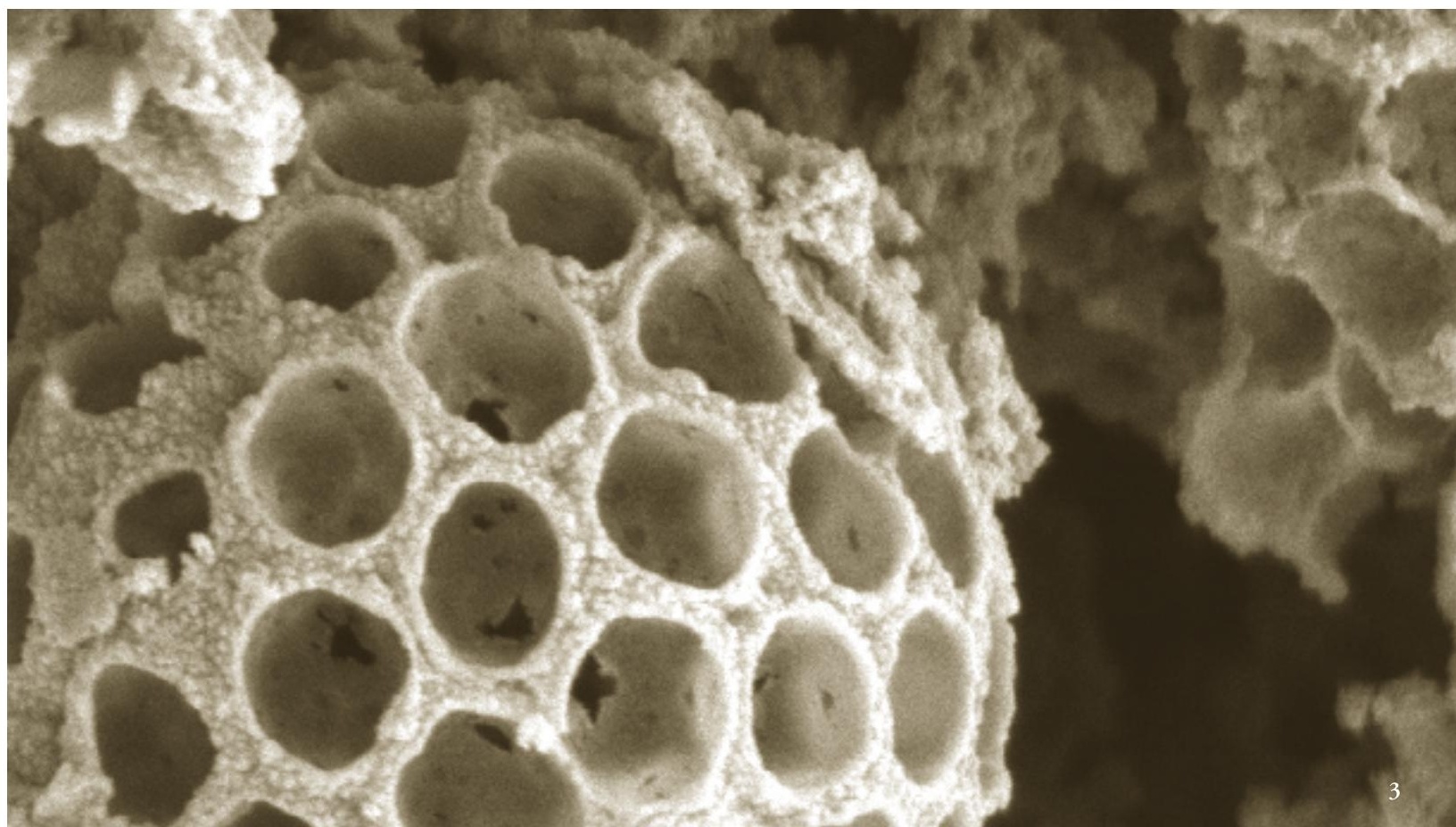




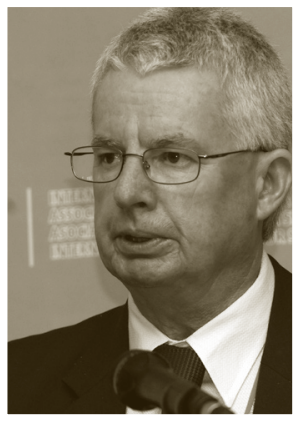

\section{Promoting Safe Use of Nanotechnologies in Australian Workplaces: The Nanotechnology OHS Research and Development Program}

\section{Tom Fisher}

Australian Government, Group Manager for the Office of the Australian Safety and Compensation Council and Federal Safety Commissioner GPO Box 9879, Canberra, Australian Capital Territory, 2601, Australia Tel: +61261219237 Fax: +61262767697

E-mail: tom.fisher@deewr.gov.au and anhthu.stuart@dewr.gov.au

Website: www.ascc.gov.au/ascc/

In May 2007, the Australian Government announced support for implementation of the National Nanotechnology Strategy (the Strategy). The Strategy will help Australia benefit from nanotechnologies while effectively addressing health, safety, environmental issues, and community concerns.

The objectives of the Strategy are to: encourage the responsible uptake of nanotechnology; ensure the effective management of health, safety, and environmental impacts; establish world class metrology capability that supports regulation and industry use; and build public confidence by providing balanced and factual information about nanotechnology.

Under the Strategy there is a particular focus on the environment, public and occupational health, and safety issues. The Australian Government has funded the Office of the Australian Safety and Compensation Council (ASCC) to establish a nanotechnology occupational health and safety research and development program (oHs Program) to help examine and address any potential oHs issues.

Four key aims of the ohs Program are to: undertake Australian nanotechnology ohs research; develop and evaluate workplace nanotechnology ohs controls; review the Australian ohs regulatory framework in relation to nanotechnology; and provide ohs support for Australian nanotechnology businesses and research organizations.

The program is primarily Australia-focused but will also contribute to global efforts relating to nanotechnology oHs through extensive consultations and collaborations with Australian and overseas researchers and policy and regulatory agencies.

Australian priorities for nanotechnology oHs policy and guidance development are currently being identified. By considering the priority materials, applications, processes, and control methodologies relevant to Australian industry and research organizations, work on potential OHs issues will target Australian needs effectively. 


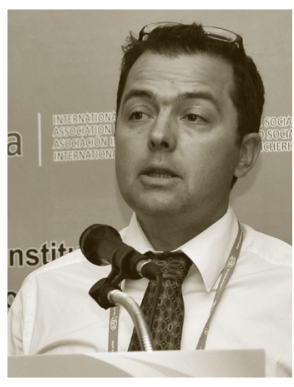
Current Methods and Requirements

Olivier Witschger

National Research and Safety Institute (INRS), France

Laboratoire de Métrologie des Aérosols

Rue du Morvan CS 60027

54519 VANDOEUVRE LES NANCY Cedex, France

Tél: +33 (0)3 83509838 Fax: +33 (0)3 83508711

Email: olivier.witschger@inrs.fr

Website: www.inrs.fr

The occupational health risks associated with engineered (i.e. produced intentionally with specific properties) nanoparticles and more generally nanostructured particles are not yet clearly understood. The studies published to date challenge conventional exposure and risk assessment approaches. Therefore, addressing the risks of engineered nanostructured particles will be among the major ongoing occupational safety and health concerns in coming years [1]. Risk is a combination of both the hazard and the potential for exposure. This paper examines one side of the risk equation, namely exposure to nanostructured particles, by addressing the following questions: How can the occupational exposures of workers and researchers be measured today? Considering the limitations of the instruments and methods available, what are the requirements for developing appropriate ones? It focuses on the inhalation of airborne nanostructured particles because the occupational health risk due to inhalation is widely hypothesized to be the most potent.

Although current knowledge is far from conclusive, it is apparent that characterizing exposures to nanoaerosols in terms of mass concentration and chemical composition does not seem appropriate under all circumstances. Therefore, conventional exposure sampling methods are limited and require careful interpretation. In addition to the two other major physical exposure metrics (i.e. number and surface area concentrations), additional nanoparticle characteristics like size, shape, degree of agglomeration/aggregation, crystallinity, charge, surface chemistry, and solubility are thought to be relevant in determining the potential health impact. Although such a full characterization cannot be carried out on a routine basis, there is a need to develop detailed and adequate knowledge of the characteristics of the nanoaerosols in work environments at risk of exposure to engineered nanoparticles; these include laboratory research development, production and manufacturing, and disposal and recycling.

There is now a battery of instruments and methods for measuring and characterizing nanoaerosols, but the majority of them have been designed for aerosol research applications rather than for occupational exposure measurements. Figure 1 summarizes the predominant 
instruments and methods currently available in terms of particle ensemble or size-resolved characterization methods, real time or off-line analysis, and the three exposure metrics: mass, number, and surface [3]. For each of the instruments, suitable particle size selective inlets need to be employed.



Figure 1: Predominant instruments and methods currently available for measuring nanoaerosols within the context of exposure characterization.

Each of the instruments and methods listed has its drawbacks (i.e. in terms of detection limit, overloading, data interpretation, off-line analysis, complexity, handling etc.), but when used in combination they may give an insight into some of the characteristics of the nanoaerosols. Besides, it is possible to derive, by combining two or more instruments together, a characteristic (i.e. related to shape or density) that could not be derived from each instrument used in isolation.

Among the major limitations of all these measurement methods are that they cannot 1) discriminate agglomerates/aggregates from single particles, and 2) distinguish engineered nanoparticles from nanometer-sized particles already present (background). In addition, most of the instruments have been developed for fixed location measurement, none having been designed as yet exclusively for personal sampling. Thus, one of the key issues when using these instruments is the sampling strategy [2]. As a minimum, this should include identifying potential sources of nanometer-sized particles (outdoor sources, industrial activities, traffic, etc.), determining the background (concentration, temporal variation etc.), understanding the ventilation system, and selecting appropriate locations. 
Surprisingly, there is a lack of knowledge concerning the performances of several of the existing instruments in relation to some of the characteristics of nanoaerosols that can be encountered in the atmospheres of workplaces. The responses of the latest instruments must therefore be studied in greater depth and adapted to exposure measurements in workplaces.

Because nanoparticles and exposure scenarios (existing and future) related to nanotechnologies are expected to be very diverse, appropriate new instruments and methods are needed. However, developing instruments per se is irrelevant unless it is considered in relation to the metric(s) that is (are) likely to be considered the most important for various conditions. Among the solutions for new instruments and methods, the ideal one should be capable of [3]: measuring different nanoaerosol characteristics simultaneously in real time (particle number, surface-area and mass concentrations, size distribution, charge), measuring in the breathing zone (portable, battery powered), and differentiating engineered nanoparticle from background being used in industrial and research workplaces (particle size and concentration ranges, robustness). Moreover, any viable new instrument should be relatively inexpensive so as to be affordable for routine measurements within a variety of companies and laboratories. Developing, testing, and making such an instrument or method available and applicable is far from being an easy task, and seems to be achievable only through targeted research and collaboration with aerosol scientists, manufacturers, toxicologists, and industrial hygienists.

Considering that materials containing nanoparticles are presently manufactured and handled by workers and researchers, and that hardly any occupational exposure experimental studies have been published, it is hoped that the points discussed in this paper will go some way to highlighting and fulfilling this significant research need.

References:

[1] Maynard A.D., Aitken R.J., Butz T., Colvin V., Donaldson K., Oberdörster G., Philbert M.A., Ryan J., Seaton A., Stone V., Tinkle S.S., Tran L., Walker N.J., Warheit D. Safe handling of Nanotechnology. Nature 2006; 267-269.

[2] ISO, Workplace Atmospheres. Ultrafine, nanoparticle and nano-structured aerosols Inhalation exposure characterization and assessment 2007. ISO/TR 27628:2007.

[3] Maynard, A. D., Aitken R.J. Assessing exposure to airborne nanomaterials: current abilities and future requirements. Nanotoxicology 2007; I(I): 26-4I. 


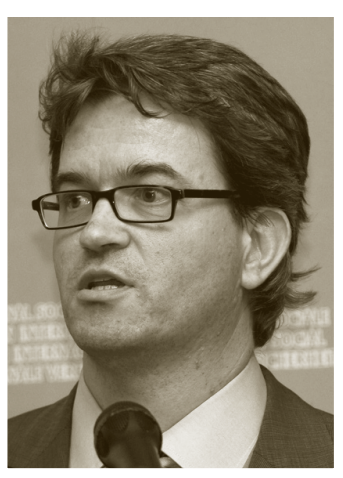

\section{Measuring Exposure to Ultrafine and Nanoparticles at Workplaces}

\section{Markus Berges}

German Social Accident Insurance (DGUV), Germany

BGIA - Institute for Occupational Safety and Health

Division 3: Hazardous substances: handling - protective measures

Sub-division: Exposure assessment

Alte Heerstraße 111

53754 Sankt Augustin Germany

Tel.: +49 (0)2241 231-2579 Fax: +49-(0)2241 231-2234

Email: Markus.Berges@dguv.de

Website: www.dguv.de/bgia

One part of the risk assessment of nanoparticles comprises the assessment of the exposure. Although the hazard from nanoparticles is not clearly defined, there appears to be a particular health risk from ultrafine dust particles and nanoparticles respectively in respiratory air. Ultrafine aerosol particles are, for the most part, by-products of thermal and chemical reactions, whereas nanoparticles are specifically engineered.

BGIA (Institute for Occupational Safety and Health of the German Social Accident Insurance (DGUV)), in conjunction with the German institutions for statutory accident insurance and prevention, carries out a measurement programme at selected workplaces. The aim is to gather and catalogue information on ultrafine and nanoparticles occurring at different work processes. Workplaces in metal processing like melting, casting, welding, soldering, cutting, laser beam processes; workplaces in glass production, vulcanization of rubber, processes in food industry like bakery or meat smokery; and workplaces on an airport field were scrutinized. The particle size distribution between approximately Ionm and 70onm and the number concentration of these particles were determined. BGIA was equipped with a suitable measurement device, a scanning mobility particle sizer (SMPS) for these particular measurements, along with instruments like a cascade impactor or aerosol samplers for the inhalable and respirable dust fraction. The number concentrations in the measurement range varied between approximately 10,000 particles per $\mathrm{cm}^{3}$ in clean areas, and up to 40,000,000 particles per $\mathrm{cm}^{3}$ in welding plumes. Peaks in particle size varied between nanometers up to a few hundred nanometers, depending on the degree of aggregation and agglomeration. We also would like to report that these are the first measurements of nanoparticles in the air.

The institutions for statutory accident insurance and prevention hope to provide thus a basis for a discussion on this topic, and improve the possible methods of prevention. 


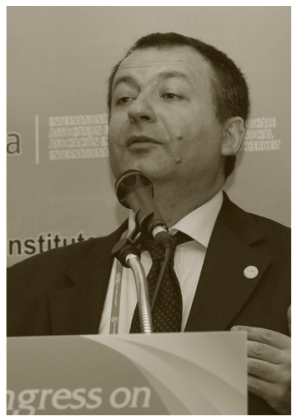

A Global Review of Safe Nanotechnology Initiatives: Research Gaps and Future Issues

\section{Sergio lavicoli}

National Institute for Occupational Safety and Prevention (ISPESL)

Dept. Of Occupational Medicine, Italy

Via Fontana Candida 1

00040 Monteporzio Catone, Rome, Italy

Tel: +390694181407

Fax: +390694181556

E-mail: sergio.iavicoli@ispesl.it; fabio.boccuni@ispesl.it

Website: www.ispesl.it/

The nanotechnologies offer opportunities for social development, but uncertainties prevail about their impact on human and environmental health. Right now there is still a huge gap between technological progress and research into the health and safety aspects of nanomaterials. Since the turn of this century, nanotechnology has grown exponentially, as confirmed by the number of products on the market and the funds dedicated to research and development in this sector. Estimates have it that by 20I4, nanotechnologies will be widely used in our society, and ten million new jobs will be created.

The international scientific community is showing increasing interest in the risks of exposure to nanomaterials in the workplace: a recent survey on research priorities in occupational safety and health run by the Italian Institute for Occupational Prevention and Safety (ISPESL), has shown that the safety of nanotechnology has received the highest score among all the priority issues in the perception of the of partner representatives involved. In this view, the following gaps and needs for the scientific knowledge come to light: limited information, difficulties in relating nanotechnologies and production of nanomaterials to specific areas of application, efforts required to assess the hazards posed by nanomaterials in realistic exposure conditions, ethical issues about nanotechnology in the workplace likely to arise from today's knowledge about the hazards of nanomaterials, and the risks nanomaterials may pose to workers.

In view of this imbalance between our scant knowledge of the potential health risks linked to the use of nanomaterials and the exponential spread of this technology likely in the near future, there is a pressing need for research focused on risk analysis for exposed workers. Finally, an integrated approach to research, cooperation, and communication strategies is essential if we are to direct our efforts towards responsible and sustainable growth of nanotechnologies. 


\section{Max Lum}

Approaches to Safe Nanotechnology: An Information Exchange with NIOSH [www.cdc.gov/niosh/topics/ nanotech/safenano/].

Nanotechnology at NIOSH [www.cdc.gov/niosh/topics/nanotech/].

National Cancer Institute, Office of Technology and Industrial Relations [http://otir.cancer.gov/].

National Nanotechnology Initiative [www.nano.gov/].

\section{Jeong Sun Yang}

2008 International Nanotech Symposium in Korea [www.nanokorea.or.kr/2008/eng/index.php].

5th Korea-US nano forum [http://nanoforum.nanonet.info/].

Korea Nanotechnology Research Society [www.kontrs.or.kr/].

Nanotechnology Research Association [www.nanokorea.net/eng/].

Resources on nanotechnology [www.nanonet.info/nanonet/wsp/english/main/index.jsp].

\section{Ogawa Yasutaka}

Current status and measures of occupational health on workers handling nanomaterials. Results obtained by a questionnaire [www.mhlw.go.jp/shingi/2008/05/dl/s0530-7a.pdf].

Preceding effort of the government on safe nanotechnology [www.mhlw.go.jp/shingi/2008/03/s0303-6d.html]. Present precautionary measures to prevent exposure to nanomaterials at workplace where they are produced or handled [www.mhlw.go.jp/shingi/2008/03/s0303-6f.html].

Research survey on appropriate control methods at fields where nanotechnology is used for research and manufacturing FY2006 [www.meti.go.jp/report/data/g7 Ioogaj.html].

The Results of a Survey on Application and Production of Nanomaterials in Japan FY2007 [www.mhlw.go.jp/ shingi/2008/04/dl/s0404-3c.pdf].

Review meeting on measures for workers to prevent chemical exposure; human hazards are unknown (draft) [www.mhlw.go.jp/shingi/2008/05/dl/s0530-7j.pdf].

\section{Tom Fisher, Howard Morris, Brett Bissett}

\section{Australian Government Departments, Research Organisations and Research Funding Agencies}

Australian Research Council (ARC) [www.arc.gov.au].

Commonwealth Science and Industrial Research Organisation (CSIRO) Niche Manufacturing Flagship [www.csiro.au]. 
Compensation Council [www.ascc.gov.au].

Department of Education, Employment \& Workplace Relations (DEEWR), Office of the Australian Safety and National Industrial Chemicals Notification and Assessment Scheme (NICNAS) [www.nicnas.gov.au].

Department of Innovation, Industry, Science and Research (DIISR) Australian Office of Nanotechnology [www.nanotechnology.gov.au].

National Health and Medical Research Council (NHMRC) [www.nhmrc.gov.au].

\section{Australian OHS Regulators}

ACT WorkCover [www.workcover.act.gov.au].

Comcare [www.comcare.gov.au].

NT WorkSafe [www.worksafe.nt.gov.au].

SafeWork SA [www.safework.sa.gov.au].

WorkCover NSW [www.workcover.nsw.gov.au].

Workplace Health \& Safety Queensland [www.deir.gld.au/workplace/].

Workplace Standards Tasmania [www.wst.tas.gov.au].

WorkSafe Victoria [www.workcover.vic.gov.au].

WorkSafe WA [www.docep.wa.gov.au/WorkSafe/].

\section{Australian Nanotechnology Industry Organisations}

Australian Nano Business Forum (ANFB) [www.anbf.com.au].

Australian Nanotechnology Alliance (ANA) [www.nanotechnology.org.au].

Nanotechnology Victoria (NanoVic) [www.nanovic.com.au].

\section{Australian Trade Unions}

Australian Council of Trade Unions (ACTU) [www.actu.asn.au].

\section{Australian OHS Professional Associations}

Australian Institute of Occupational Hygienists [www.aioh.org.au].

\section{Australian Research Networks}

Australian Research Council Nanotechnology Network (arcnn) [www.ausnano.net].

NanoSafe Australia [www.rmit.edu.au/NANOSAFE].

\section{Australian Institutions undertaking OHS/toxicology research}

CSIRO Niche Manufacturing Flagship, Nanosafety Theme [www.csiro.au].

Macquarie University [www.mq.edu.au].

Monash University [www.monash.edu.au].

RMIT University [www.rmit.edu.au].

University of New South Wales [www.unsw.edu.au].

University of Queensland, Australian Institute of Bioengineering \& Nanotechnology [www.aibn.uq.edu.au/]. 
University of Queensland, School of Medicine [www.som.uq.edu.au/som/].

University of Western Australia, Centre for Strategic Nano-fabrication [www.strategicnano.uwa.edu.au].

\section{Australian Legal Researchers}

Monash University, Centre for Regulatory Studies [www.law.monash.edu.au/regstudies/].

\section{Australian Nanotechnology OHS Programs}

DEEWR Nanotechnology OHS Program [www.ascc.gov.au/ascc/HealthSafety/EmergingIssues/Nanotechnology/].

\section{Australian Publications}

DEEWR [2006]. A Review of the Potential Occupational Health and Safety Impacts of Nanotechnology [www.ascc.gov.au/NR/rdonlyres/ACi7BA49-8BAI-43B8-BCo8-2 I9DE5378 IE6/o/

ASCCReviewOHSImplicationsNanotechnology2006.pdf].

Harford A., Edwards J., Priestly B. and Wright P. [2007]. Current oHs best practices for the Australian

Nanotechnology industry. Journal of Occupational Health and Safety - Australia and New Zealand, 23(4):315-33 [www.nanovic.com.au/downloads/Nano_OHS_Best_Practice_Nov_2007.pdf].

Invest Australia [2007]. Nanotechnology: Australian Capability Report, Third Edition [www.anbf.com.au/PDF/NANOREPORTo7\%2oFinal.pdf].

NICNAS [2007]. Summary of call for information on the use of Nanomaterials [www.nicnas.gov.au/Publications/ Information_Sheets/General_Information_Sheets/NIS_Call_for_info_Nanomaterials.pdf].

\section{Olivier Witschger}

Honnert B., Vincent R. [2008] Production et utilisation industrielle des particules nanostructurées. Hygiène et Sécurité au Travail, pp. 5-5 [www.hst.fr].

INRS. Dossier "Les Nanomatériaux” [www.inrs.fr].

INRS et EDP Sciences. Les nanoparticules. Un enjeu majeur pour la santé au travail? Avis d'experts. 2007. ISBN 978-2-86883-995-4. 704 P.

Ricaud M., Lafon D., Roos F. [2008] Les nanotubes de carbone : quels risques, quelle prévention? Hygiène et Sécurité au Travail, pp. 43-57 [www.hst.fr].

Witschger O., Fabries J.F. [2005] Particules ultra-fines et santé au travail. I - Caractéristiques et effets potentiels sur la santé. Hygiène et Sécurité au Travail, pp. 2I-35 [www.hst.fr].

Witschger O., Fabries J.F. [2005] Particules ultra-fines et santé au travail. 2 - Sources et caractérisation de l'exposition. Hygiène et Sécurité au Travail, pp. 37-54 [www.hst.fr].

\section{Markus Berges}

BGIA - Institut für Arbeitsschutz der Deutschen Gesetzlichen Unfallversicherung [www.dguv.de/bgia/de/fac/nanopartikeln/index.jsp]. 
Bundesanstalt für Arbeitsschutz und Arbeitsmedizin (BAuA) [www.baua.de/en/Topics-from-A-to-Z/HazardousSubstances/Nanotechnology/Nanotechnology.html?_nnn=true\&_nnn=true].

European Commission's site on Nanotechnology [http://cordis.europa.eu/nanotechnology/].

European Nanotechnology Gateway [www.nanoforum.org].

Federal Ministry of Education and Research [www.bmbf.de/en/nanotechnologie.php].

Federal Ministry for the Environment, Nature Conservation and Nucleas Safety [www.bmu.bund.de/english/nanotechnology/general_information/doc/37323.php].

NanoCare (German Research Project) [www.nanopartikel.info/].

NanoSafe 2 (EU fr6 Project) [www.nanosafe.org/].

NANOSH (Eu FP6 Project) [www.ttl.fi/Internet/partner/Nanosh/Main+Page/].

\section{Sergio lavicoli, Fabio Boccuni}

Boccuni F, Rondinone B, Petyx C and Iavicoli S. Potential occupational exposure to manufactured nanoparticles in Italy. Journal of Cleaner Production 2008; I 6: 949-956. [www.sciencedirect.com/ science?_ob=ArticleURL\&_udi=B6VFX-4PIG8RJ-2\&_user=3952388\&_rdoc=1\&_fmt=\&_orig=search \&_

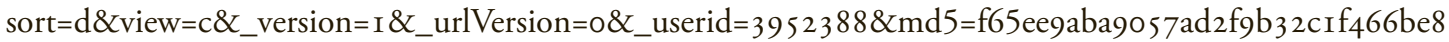
b2].

European Commission [2000]. Communication from the Commission of the European Communities on Precautionary Principle (сом) [www.gdrc.org/u-gov/precaution-4.html].

European Commission. Sixth Framework Programme [http://cordis.europa.eu/fp6/projects.htm].

Nanotec IT. Italian Center for Nanotechnolgy [www.nanotec.it/]. 







\section{Delivering on the Nation's promise: Safety and health at work for all people through research and prevention}

SAFER • HEALTHIER • PEOPLE

U.S. Department of Health and Human Services

Centers for Disease Control and Prevention

National Institute for Occupational Safety and Health

To receive NIOSH documents or more information about occupational safety and health topics, please contact $\mathrm{NIOSH}$ :

Telephone: 1-800-cdc-info (1-800-232-4636)

TTY: 1-888-232-6348

email: cdcinfo@cdc.gov

or visit the NIOSH Web site at www.cdc.gov/niosh

For a monthly update on news at NIOSH, subscribe to NIOSH eNews by visiting www.cdc.gov/niosh/eNews.

DHHS (NIOSH) Publication No. 2009-130 